\title{
Interstate disparities in the performances in combatting COVID-19 in India: efficiency estimates across states
}

\author{
Shrabanti Maity ${ }^{*^{*}}$ (D), Nandini Ghosh² ${ }^{2}$ and Ummey Rummana Barlaskar ${ }^{3}$
}

\begin{abstract}
Background: Currently, the novel coronavirus or COVID-19 pandemic poses the greatest global health threat worldwide, and India is no exception. As an overpopulated developing country, it is very difficult to maintain social distancing to restrict the spread of the disease in India. Under these circumstances, it is necessary to examine India's interstate performances to combat COVID-19.

This study aims to explore twin objectives: to investigate the comparative efficiency of Indian states to combat COVID-19 and to unfold the factors responsible for interstate disparities in the efficiency in combatting COVID-19.

Methods: The stochastic production frontier model was utilized for data analysis. The empirical analysis was facilitated by the inefficiency effects model, revealing the factors that influence interstate variability in disease management efficiency. Three types of variables, namely, output, inputs, and exogenous, were used to measure health system efficiency. The relevant variables were compiled from secondary sources. The recovery rate from COVID-19 was the output variable and health infrastructures were considered as the input variable. On the contrary, the non-health determinants considered to have a strong influence on the efficiency of states' disease management, but could not be considered as input variables, were recognised as exogenous variables. These exogenous variables were specifically used for the inefficiency analysis.

Results: The empirical results demonstrated the existence of disparities across Indian states in the level of efficiency in combatting COVID-19. A non-trivial outcome of this study was that Tamil Nadu was the best performer and Manipur was the worst performer of the investigated states. Variables such as elderly people, sex ratio, literacy rate, population density, influenced the efficiency of states, and thus, affected the recovery rate.
\end{abstract}

Conclusion: This study argues for the efficient utilisation of the existing health infrastructures in India. Simultaneously, the study suggests improving the health infrastructure to achieve a long-run benefit.

Keywords: COVID-19, Stochastic production frontier, Inefficiency effects, Recovery rate

\footnotetext{
* Correspondence: sontoshe_sraban@yahoo.in

'Department of Economics, Vidyasagar University, Paschim Midnapore, Midapore, West Bengal, India

Full list of author information is available at the end of the article
}

(c) The Author(s). 2020 Open Access This article is licensed under a Creative Commons Attribution 4.0 International License, which permits use, sharing, adaptation, distribution and reproduction in any medium or format, as long as you give appropriate credit to the original author(s) and the source, provide a link to the Creative Commons licence, and indicate if changes were made. The images or other third party material in this article are included in the article's Creative Commons licence, unless indicated otherwise in a credit line to the material. If material is not included in the article's Creative Commons licence and your intended use is not permitted by statutory regulation or exceeds the permitted use, you will need to obtain permission directly from the copyright holder. To view a copy of this licence, visit http://creativecommons.org/licenses/by/4.0/ The Creative Commons Public Domain Dedication waiver (http://creativecommons.org/publicdomain/zero/1.0/) applies to the data made available in this article, unless otherwise stated in a credit line to the data. 


\section{Background}

Millions of people worldwide are affected by severe acute respiratory syndrome coronavirus 2 (SARS-CoV2 ), caused by the disease commonly known as COVID19, rendering the disease a pandemic within a few months of the first case of infection. Combatting COVID-19 is a major challenge to all countries especially in the current situation with no vaccine or medicine for the treatment of the disease. Moreover, COVID19is highly contagious, making it capable of rapidly spreading across the world. The World Health Organization (WHO) declared the disease a public health emergency of international concern [34]. Thus, countries have a very limited time to prepare for a battle against the unseen opposition. This fight more challenging for developing and underdeveloped countries with limited medical infrastructure, huge population pressure, backward economic conditions, amongst other problems. In this situation, containment, social distancing, and maintaining a healthy habit are criteria of the highest priority to confront the disease.

India is a developing country with a population of 136.64 crores, $2^{\text {nd }}$ worldwide in terms of population size [29-31] and 19th in population density [29-31]. The World Bank [33] indicated that 24\% of people live in densely populated slum areas in India (https://data. worldbank.org). Therefore, it is very difficult to maintain social distancing and stop the disease from spreading.

In India, the first case of COVID-19 infection was confirmed on 30th January 2020 in the state of Kerala. The complete lockdown was implemented in India on 24th March 2020, when only 564 people are infected by COVID-19 [4]; however, the number of infected persons continually increases and reached $1,97,945$ on 25th May 2020. India is comprised of 28 states and 8 union territories. The rate of infection and the recovery rates vary across different states. Several factors are also involved in the successful management of COVID-19 outbreaks in the states. Lu et al. [19], investigate the impact of quarantine on mental health. In this study, a comprehensive number of pertinent literature is reviewed to understand the outcomes of different dimensions of COVID-19. However, the specific issue of interstate disparities in the efficiency of controlling the COVID-19 is not properly addressed, and it's the first of its kind to address this issue. This backdrop motivates us to pursue this study. Accordingly, the objective of this study is twofold: the initial objective is to investigate the comparative efficiency of different Indian states to combat COVID-19 and also attempt to unfold the factors responsible for interstate divergences of efficiency in combatting COVID-19.

From the concept of the neoclassical production function, efficiency is defined as an act of the economic agent to produce a specified output at minimum costs.
This implies that the economic unit should choose inputs to minimise the production costs. However, concerning healthcare, the aftermath is the most important factor. Thus, health care efficiency fundamentally concerns the advancement of an individual's health. This can be accomplished in two alternative ways, either maximum utilisation of current input level or enlargement of the available inputs to attain a higher outcome level. This can be implemented by identifying the health agents with better performance than others and exploring the constituents that help amplify their performances. Thus, a stochastic production frontier model for health economics could be specifically formulated. There exists pertinent literature concerning the application of stochastic production frontier model for assessing the performances of the health system. Studies which advocates the superiority of the stochastic production frontier approach for estimating the efficiency of health service providers, e.g., hospitals etc., are- Wagstaff [32], Hofler and Rungeling [15], Zuckerman et al. [36], Defelice and Bradford [9], Chirikos [5], Gerdtham et al. [13], Chirikos and Sear [6] and Street and Jacobs [28]. Moreover, studies by Murray and Frenk [22], Evans et al. [10], Sankar and Kathuria [25], Kathuria and Sankar [18], Forbes et al. [12], Hamidi [14] and Yildiz et al. [35], endorse that the 'Stochastic Frontier Approach (SFA)' is a robust approach to measure the efficiency of the health service.

This study is structured as follows. First, the conceptual framework is discussed after the introduction. In "Methodology" section, the data sources, variables, and the stochastic frontier model utilised for the empirical study are discussed. The empirical results and discussion are presented in "Results" section. Finally, "Conclusion" section concludes and draws policy implications.

\section{Methods \\ Conceptual framework}

In an attempt to recon the efficiency of different Indian states in combatting COVID-19, the notion of health system efficiency is elucidated following Murray and Frenk [22] and Evans et al. [10]. Following Murray and Frenk [22] and Evans et al. [10], the desired aim (goal) of the health system, in our case the 'recovery rate of COVID-19', was measured on the vertical axis as shown in Fig. 1.

The inputs to attain the desired outcome were measured on the horizontal axis. The upper line in the figure delineates the maximum possible health aftermath attainable from the given set of health inputs. In the literature, it is designated as 'frontier'. The lower line in the figure portrays the level of attainable health sequelae in the absence of any health system. The principal contrast between the farm output and health system outcome is that in the absence of inputs, farm output would be zero. 
Attainable health system (Recovery Rate of COVID-19)

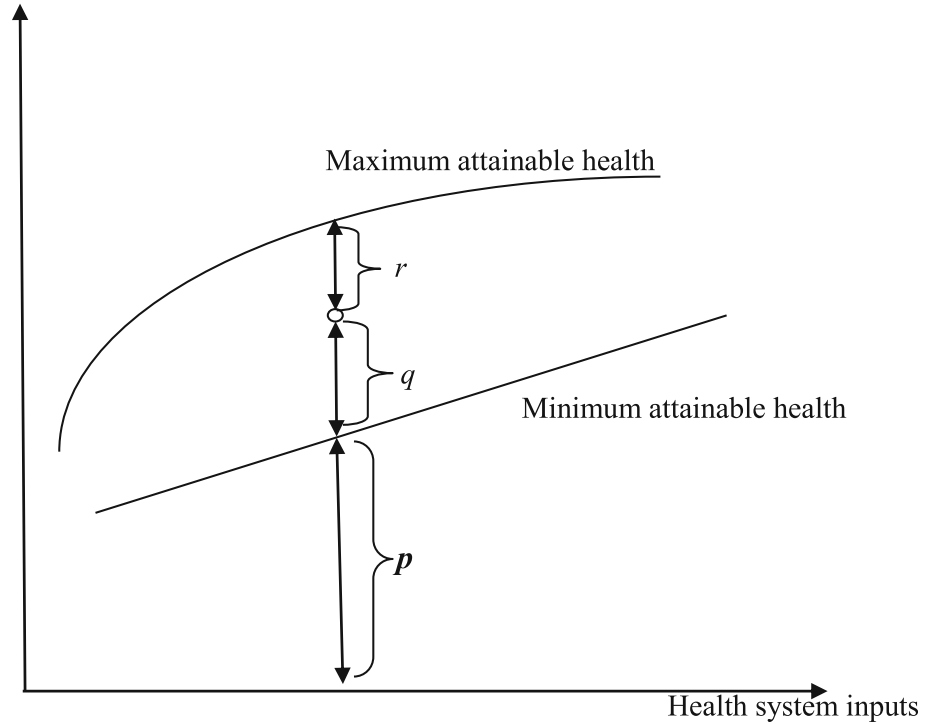

Fig. 1 Health System Performance. Source: Adapted from Murray and Frenk [22] and Evans et al. [10]

However, the health outcome would not be zero in the absence of any health expenditures, as all individuals in a nation will not die simultaneously.

We presumed that the country and/or the state had accomplished $(p+q)$ units of health outcomes. The maximum possible attainable health outcome was $p+q+r$ (see Fig. 1). Under this diegesis, 'system performance' is defined as [10, 22]:

$$
q /(q+r)
$$

where $(q+r)$ is the potential outcome and $q$ is the level of health outcome achieved.

Thus, Eq. (1) can be interpreted as the 'system achieves compared to its potential' [22]. The question is how to measure the performance of the health system systematically; thus, we can permit inter -, intra -, and/ or state comparisons over time. This is thoroughly examined in this study in the context of combatting COVID-19.

In the 'frontier' framework, 'technical efficiency' is defined as the 'farm's capability to produce the maximum possible output from a given set of inputs'. It is measured by the ratio of the observed to the maximum achievable outputs. In terms of Fig. 1 it, the ratio, $(p+q) /(p+q+$ $r$ ). It is known as the output-based measure of technical efficiency' [20]. Thus, this definition was adopted to measure the performance of the health system of the states in combatting COVID-19 because in health system performance we are willing to measure the relationship between what the system attains relative to its potential. Thus, according to this definition, health system efficiency was considered synonymous with health system performance. In the subsequent discussion, the term 'efficiency' will be used to allude to 'system performance'. In this study, we examined the measurement of technical efficiency only by using the 'stochastic frontier approach' (SFA) by considering availability and access of health care infrastructures as inputs and health sector performance as a single output. In this study, we examined the inefficiency effects of the stochastic production frontier Battese and Coelli [2]. Thus, the estimation followed a two-step procedure. First, the efficiency score of the different states of India was measured, and second, the components responsible for the differences in the performances of different Indian states in combatting COVID-19 were identified. The details specification of the econometric model is presented next.

\section{Methodology}

This section discusses the data sources, the corresponding variables, and theoretical underpinning of the application of stochastic frontier analysis in health economics. This helps in formulating the stochastic production frontier (SPF) model to investigate the study objectives.

\section{Data}

The study is entirely premised on secondary data compiled from various secondary sources. This study investigates 21 states and 1 Union Territory of India. The remaining Indian states and Union Territories are excluded due to the lack of available relevant data. The included states were Andhra Pradesh, Arunachal Pradesh, Assam, Bihar, Chhattisgarh, Gujarat, Haryana, 
Table 1 Descriptions of the variables $[11,16,17,23,24]$

\begin{tabular}{|c|c|}
\hline Variables & Definition \\
\hline Recovery Rate (RR) (y) & $\begin{array}{l}\text { Shows the ratio of total number of persons recovered } \\
\text { from Covid-19 to total number confirmed cases. The } \\
\text { variable is calculated by the authors based on total } \\
\text { number of persons recovered from Covid-19 and total } \\
\text { number confirmed cases. }\end{array}$ \\
\hline $\begin{array}{l}\text { Doctor-population ratio per } \\
1000 \text { (DOCTOR) }\left(x_{1}\right)\end{array}$ & $\begin{array}{l}\text { Shows the ratio of number of government allopathic } \\
\text { doctors and population served in India per } 1000 \\
\text { population. The variable is calculated by the authors based } \\
\text { on the number of government allopathic doctors and } \\
\text { population served in India. Then the ratio is transferred for } \\
\text { per } 1000 \text { population. }\end{array}$ \\
\hline $\begin{array}{l}\text { Nurses- population ratio per } \\
1000 \text { population (NURSE) }\left(x_{2}\right)\end{array}$ & $\begin{array}{l}\text { Shows the total number nurses served per } 1000 \\
\text { population. }\end{array}$ \\
\hline $\begin{array}{l}\text { Total Police per lakh of } \\
\text { population (Police) }\left(x_{3}\right)\end{array}$ & $\begin{array}{l}\text { Shows number of police person served per lakh } \\
\text { population. }\end{array}$ \\
\hline $\begin{array}{l}\text { Num Isolation Beds (Isolation } \\
\text { beds) }\left(x_{4}\right)\end{array}$ & $\begin{array}{l}\text { Total number of isolation beds available for COVID-19 } \\
\text { patient. }\end{array}$ \\
\hline $\begin{array}{l}\text { Total People In Quarantine } \\
\text { (Quarantine) }\left(x_{5}\right)\end{array}$ & Total number of people kept in quarantine for observation. \\
\hline $\begin{array}{l}\text { Number of ICU beds (ICU } \\
\text { beds) }\left(x_{6}\right)\end{array}$ & $\begin{array}{l}\text { The total number of intensive care unit beds available for } \\
\text { the care of Covid-19 affected patients }\end{array}$ \\
\hline
\end{tabular}

the care of Covid-19 affected patients
Number of ventilators (Ventilators) $\left(x_{7}\right)$
The total number of ventilators available for the aiding artificial respiration during severe respiratory distress of Covid-19 affected patients

Total number of laboratories for testing patient bio-fluid for Input Covid-19

Shows the total number of person actually tested for covid- Input 19.

Refers the percentage share of 60 and above population in the total population.

Shows the number of female population per 1000 male population.

Defined as total number of literate persons in a given age group, expressed as a percentage of the total population in that age group

Urbanisation (\%) (Urban) $\left(z_{4}\right)$

Number of persons per room used for sleeping (Sleep) $\left(z_{5}\right)$

Percentage of self reported diabetes between age 15-49 (Diabetes) $\left(z_{6}\right)$

Percentage of self reported heart disease between age 15-49 (Heart) ( $\left.z_{7}\right)$

Population density $/ \mathrm{km} 2$ (Population density) ( $\left.z_{8}\right)$

Per capita NSDP (PCNSDP) $\left(z_{9}\right)$ areas.

Average number of persons using a single room for sleeping

The percentage of people between 15 and $49 \mathrm{yrs}$. of age in a population who have reported that they are suffering from diabetes

The percentage of people between 15 and $49 \mathrm{yrs}$. of age in a population who have reported that they are suffering

Number of people living per square kilometre area

Net State Domestic Product (NSDP) is defined as a measure, in monetary terms, of the volume of all goods

\section{Category Data source}

Output

Ministry of Health and Family Welfare, GOI.

Retrieve from: https://www.mohfw.gov.in/

Input Directorate of State Health Services \& National Health Profile. Retrieve from: http:// www.cbhidghs.nic.in/

Input Indian Nursing Council. Retrieve from: http://www.indiannursingcouncil.org/

Input Ministry of Home Affairs. Retrieve from: https://www.mha.gov.in/

Input Retrieve from: https://www.covid19india. org/

Retrieve from: https://www.covid19india. org/

Input COVID-19 modelling estimates for India by a team of researchers

affiliated with CDDEP and Princeton University, https://cddep.org/covid-19/ hospital-capacity-in-india/india/

Input COVID-19 modelling estimates for India by a team of researchers

affiliated with CDDEP and Princeton University, https://cddep.org/covid-19/ hospital-capacity-in-india/india/

Indian Council of Medical Research (ICMR) report, 2020. Retrieve from: https://main. icmr.nic.in/

Retrieve from:

https://www.covid19india.org

Exogenous Census of India, 2011 (For reference check reference list in the manuscript).

Exogenous Census of India, 2011

Exogenous Census of India, 2011

Exogenous Census of India, 2011 from heart disease and services produced within the boundaries of the State during a given period of time after deducting depreciation, divided by total number of population.
Exogenous Census of India, 2011

Exogenous National Family Health Survey-4, 2015-16, (For reference check reference list in the manuscript).

Exogenous National Family Health Survey

Exogenous National Family Health Survey

Exogenous Handbook of Statistics on Indian States, Reserve Bank of India, (For reference check reference list in the manuscript) 
Table 1 Descriptions of the variables [11, 16, 17, 23, 24] (Continued)

\begin{tabular}{|c|c|c|c|}
\hline Variables & Definition & Category & Data source \\
\hline $\begin{array}{l}\text { Regular wage/Salaried } \\
\text { Employee (\%) (Employment) }\left(z_{10}\right)\end{array}$ & $\begin{array}{l}\text { Shows the percentage share of workers engaged in } \\
\text { regular salaried employment. }\end{array}$ & Exogenous & $\begin{array}{l}\text { NSS, 68th Round, 2011-12, (For reference check } \\
\text { reference list in the manuscript). }\end{array}$ \\
\hline $\begin{array}{l}\text { Internet subscriptions (per } \\
\text { lakh population.) } \\
\text { (Digitalisation) }\left(z_{11}\right)\end{array}$ & Shows rate of internet subscription per lakh population. & Exogenous & $\begin{array}{l}\text { Telecom Regulatory Authority of India. Retrieve } \\
\text { from: https://www.trai.gov.in/ }\end{array}$ \\
\hline
\end{tabular}

Source: Authors' own specification

Jharkhand, Karnataka, Kerala, Madhya Pradesh, Maharashtra, Manipur, Meghalaya, Orissa, Punjab, Rajasthan, Tamil Nadu, Uttar Pradesh, Uttarakhand and West Bengal and the union territory was Delhi. The study examined 20 independent variables, nine of which were input variables and 11 were exogenous variables. The variables were collected from various secondary sources. Table 1 provides a comprehensive summary of the variables and their sources.

Table 1 shows the recovery rate from COVID-19, the output variable which was calculated as the percentage of recovery from COVID-19 and the total confirmed cases up to 25th May 2020.

\section{Variables}

Three types of variables are indispensable for measuring health system efficiency using the "stochastic production frontier model" [10, 18, 25]. First, it is imperative to pinpoint a pertinent output indicator that represents the performance of the health sector. Second, it is mandatory to recognise a pertinent set of inputs that have an influence on the production of the output. Finally, it is highly recommended that variables that can affect the outcome of the health sector positively or negatively, but cannot be recognised as the inputs for the concerned output, are also included. These variables are non-health variables, categorised as 'exogenous' variables. These exogenous variables seize the effects of non-health variables on health outcomes.

\section{Output variable}

Under pandemic circumstances, ensuring its citizens are safe and healthy is the most significant concern of the central and state government of India. India is a highly populated country with a population density of 1202 people per $\mathrm{mi}^{2}$. Under such circumstances, COVID-19 may lead to catastrophic outcomes for India. In this, we consider 'the rate of recovery' from COVID-19 in different states of India as the output variable.

\section{Input variables}

Apropos input variables have two alternatives: either to use the monetary expenditures on health (such as percapita expenditures on public health) or physical inputs. Due to the lack of data available, we decided to consider physical health inputs, which refer to the numbers of health care professionals, police, hospital facilities, etc. (Table 1). It is noteworthy that as population and area fluctuate across states, the variations in population size affect the access to available health facilities. Therefore, the ratios of different parameters with population size were calculated to obtain a clear picture of the available input variables per capita.

\section{Exogenous variables}

It is a well-established fact that improved health is not an exclusive outcome of the health service providers [22]. This is also true for combatting COVID19. Some pioneering studies highlighted the influence of non-health determinants, such as income and educational level, measured differently $[3,26]$. In this study, we investigated several variables that have a significant influence on the efficient control of COVID-19 across different states of India. However, these variables could not be categorised as input variables, and so these variables were categorised as exogenous variables. These variables were exclusively considered for the analysis of inefficiency effects and are listed in Table 1. It is worth noting that all the variables, viz., output, inputs and exogenous are representing the total figures of the Indian states, including both rural and urban statistics.

\section{Econometric model}

Fundamentally, a stochastic frontier production function for the cross-sectional data can be manifested as follows:

$$
y_{i}=f\left(x_{i}, \beta\right) \exp \left(V_{i}\right) T E_{i}
$$

Where, $\mathrm{y}$ is the health outcome, $x$ and $\beta$ stand for the vector of arguments of the production function, viz., access and availability of the health infrastructure inputs, which are directly influencing the health outcomes and the vector of the coefficients respectively; all the variables being expressed in logarithm. $\exp \left(V_{i}\right)$ is the random error term and the subscript $i$ refers to the particular crosssection, viz., the $i$ th state.

The firm-specific technical efficiency Battese and Coelli [2] which is assumed to be random variable may 
be written as: $T E_{i}=\exp \left(-U_{i}\right)$. Since $T E_{i} \leq 1$, hence $U_{i} \geq 0$, i.e., this error is one-sided. So, we can write (2) as:

$$
y_{i}=f\left(x_{i}, \beta\right) \exp \left(V_{i}\right) \exp \left(-U_{i}\right)
$$

Here the assumptions are that $V_{i} \sim \operatorname{IIDN}\left(0, \sigma_{V}^{2}\right)$ and $U_{i} \sim \operatorname{IIDN}\left(z_{i} \delta, \sigma_{U}^{2}\right)$.

Where $z_{i}$ a $(1 x \mathrm{~m})$ vector of explanatory variables is associated with the technical inefficiency of production across states and $\delta$ is an $(m x 1)$ vector of unknown coefficients.

Further $U_{i}$ and $V_{i}$ are independent of each other and also independent of $x_{i}$. So, the underlying model is Normal-Truncated Normal [27].

It is noteworthy that the component $V_{i}$ captures random variation in output due to factors outside the control of the state (suchlike, non-reporting of COVID-19 cases, etc.), which is uncontrollable and can be considered as the "act of God". On the contrary, $U_{i}$ reflects technical inefficiency on the part of the state and it is controllable. The technical efficiency [1] of the health sector for the ith state, $T E_{i}$, in the stochastic frontier model (3) could be specified in Eq. (4).

$$
T E_{i}=\exp \left(-U_{i}\right)=\exp \left(-z_{i} \delta-W_{i}\right)
$$

The random variable, $W_{i}$ is defined by the truncation of the normal distribution with zero mean and variance $\sigma_{U}^{2}$, such that the point of truncation is $-z_{i} \delta$, that is, $W_{i} \geq$ $-z_{i} \delta$. These assumptions are consistent with $U_{i}$ being a non-negative truncation of the $N\left(z_{i} \delta, \sigma_{U}^{2}\right)$ distribution.

The maximum likelihood estimation technique is the best way to estimate simultaneously the parameters of the stochastic frontier and the technical inefficiency model [2]. The likelihood function is expressed in terms of the variance parameters [1], viz.,

$\sigma^{2}=\sigma_{V}^{2}+\sigma_{U}^{2}$ and $\gamma=\frac{\sigma_{U}^{2}}{\sigma^{2}}$, where $\gamma$ lies between 0 and 1 depending on the dominance of $\sigma$ and $\sigma_{u}$ respectively. Maximum-likelihood estimations (MLE) of equations and the corresponding efficiency scores of the listed states are obtained by using the FRONTIER-4.1 programme [7].

Accordingly, following Battese and Coelli [2], the model is estimated in terms of the following equation:

$\ln \left(R R_{i}\right)=\alpha_{0}+\alpha_{\text {DOCTOR }} \ln ($ DOCTOR $)+\alpha_{\text {NURSE }} \ln ($ NURSE $)+\alpha_{\text {Police }} \ln ($ Police $)+$ $\alpha_{\text {Isolation beds }} \ln ($ Isolation beds $)+\alpha_{\text {Quarantine }} \ln ($ Quarantine $)+\alpha_{\text {ICU beds }} \ln ($ ICU beds $)+$ $\alpha_{\text {Ventilators }} \ln ($ Ventilators $)+\alpha_{\text {Labs }} \ln ($ Labs $)+\alpha_{\text {Tested }} \ln ($ Tested $)+\left(V_{i}-U_{i}\right)$

Where, $\ln$ is the natural logarithm (i.e., to the base $e$ ), $\alpha_{0}$ is the intercept term and $\alpha_{j} \mathrm{~s}$ are the vector of the coefficients measuring the effects of the corresponding vector of arguments of the production function, viz., access and availability of the health infrastructure inputs, which are directly influencing the health outcomes.
The technical inefficiency effects were presumed to be defined by the following equation:

$$
\begin{aligned}
U_{i}= & \delta_{0}+\delta_{\text {Elderly }} \ln (\text { Elderly })+\delta_{S R} \ln (S R) \\
& +\delta_{\text {LR }} \ln (\text { LR })+\delta_{\text {Urban }} \ln (\text { Urban }) \\
& +\delta_{\text {Sleep }} \ln (\text { Sleep })+\delta_{\text {Diabetes }} \ln (\text { Diabetes }) \\
& +\delta_{\text {Heart }} \ln (\text { Heart }) \\
& +\delta_{\text {Population density }} \ln (\text { Population density }) \\
& +\delta_{\text {PCNSDP }} \ln (\text { PCNSDP }) \\
& +\delta_{\text {Employment }} \ln (\text { Employment }) \\
& +\delta_{\text {Digitalisation }} \ln (\text { Digitalisation })+W_{i}
\end{aligned}
$$

The vectors $\delta \mathrm{s}$ apprehend the effects of the technical inefficiency of production across states.

Equations (5) and (6) are estimated using FRONTIER 4.1 [7].

\section{Results}

The empirical results of our estimated econometrics and others are discussed in the following.

\section{State-wise recovery rate from COVID-19 in India}

The COVID-19 pandemic had a very high metamorphosis and rate of infection. Although India is a densely populated country, prominent steps of the Indian government have limited the COVID-19 death toll to approximately $5 \%$ of total infected cases. Considering the country's immense population, the death rate is under control, although even a single death from COVID-19 would cause distress. The recovery rate of COVID-19 patients varied across the states. Figure 2 presents an overview of the state-wise recovery rate of COVID-19 in India.

Examination of the figure shows that the states' recovery rates range from 100\% (Arunachal Pradesh) to $12.5 \%$ (Manipur). The highest recovery rate from COVID-19 was identified in Arunachal Pradesh, followed by Punjab (92.14\%). On the contrary, the lowest rate was identified in Manipur, followed by another north-eastern state, Assam (14.55\%). The union territory Delhi was $11^{\text {th }}$ in recovery rate with $48.74 \%$. The trends of the two northeastern states, Arunachal Pradesh and Assam, are noteworthy. These discrepancies in recovery rate may be attributable to the differences in the efficiency of existing health infrastructure utilisation amongst the states for combatting COVID-19. Furthermore, states with equal efficiency in combatting COVID-19 that had different recovery rates may be explained by exogenous factors influencing the state's efficiency. In the subsequent sections, we discuss the variables that affect the efficiency of the states in combatting COVID-19. 


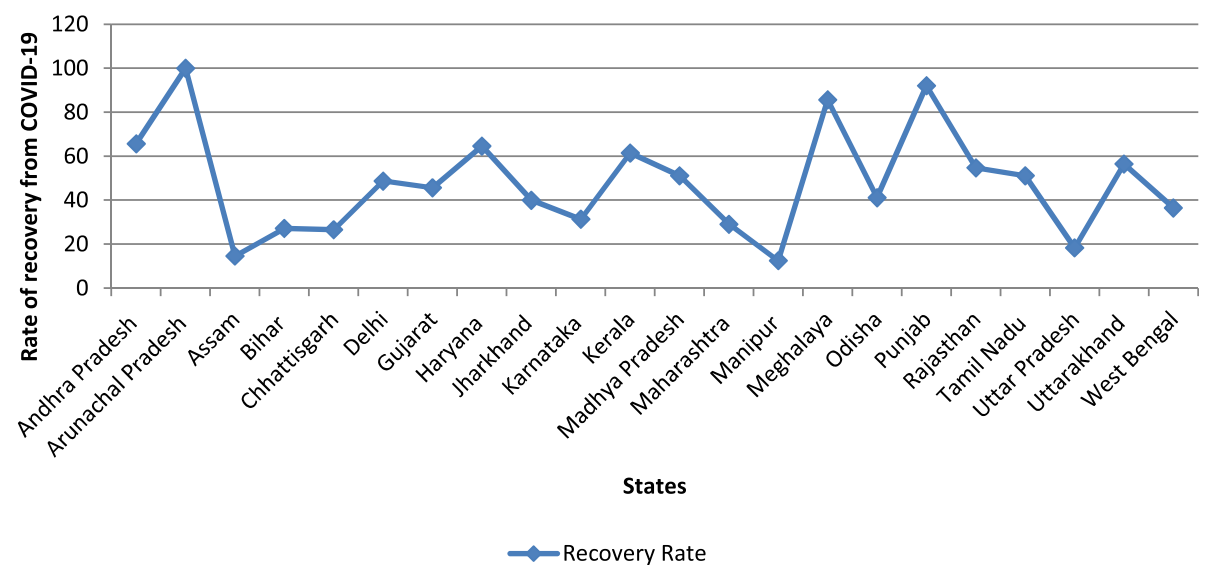

Fig. 2 Interstate recovery rate from COVID-19. Source: Authors' own graphical presentation

\section{Efficiency analysis of different states in India}

This section explores the main objective of this study, namely, the comparison of India's interstate disparities in the efficiency in combatting COVID-19. However, we must first check the heterogeneity in the data. Descriptive statistics were imperative to understand the heterogeneity in the data, which is a paramount condition for any cross-sectional study. The descriptive statistics presented in Additional file 1: Table S1 confirm the heterogeneity in the data. The efficiency score and the corresponding ranking of the states based on the efficiency score are presented in Table 2. It is noteworthy that the corresponding efficiency score of the Indian states in conbatting COVID-19 are obtained by using the FRONTIER-4.1 programme developed by Coelli [7]. Significantly, relative efficiency scores exhibited how efficiently the states were performing in combatting COVID-19 in comparison to the most efficient state. The analysis of the relative health sector efficiency in combatting COVID-19 of the states was performed by considering the overall mean efficiency score of 0.709 as the benchmark of efficiency $[8,21]$. It is worth noting that the corresponding value of S.D. is 0.232 . The small value of S.D. also vindicates the use of mean efficiency score as the benchmark of efficiency for the comparison across Indian states. Consequently, a state would be categorised as relatively technically more efficient than other states if the achieved concerned state's efficiency score was higher than mean efficiency and vice-versa. For example, West Bengal's efficiency score was 0.932 higher than the overall mean efficiency score of 0.709 . Thus, West Bengal was considered as a technically efficient state in combatting COVID-19 relative to other Indian states [8, 21]. Applying this benchmark, 14 of 22 Indian states were identified to be performing amply in combatting COVID-19, meaning 64\% of Indian states were performing satisfactorily to combat COVID-19.
Table 2 Efficiency estimates and ranking for different states of India

\begin{tabular}{|c|c|c|}
\hline States & Efficiency score & Ranking \\
\hline Andhra Pradesh & 0.892 & 5 \\
\hline Arunachal Pradesh & 0.697 & 16 \\
\hline Assam & 0.217 & 21 \\
\hline Bihar & 0.735 & 11 \\
\hline Chhattisgarh & 0.335 & 20 \\
\hline Delhi & 0.938 & 2 \\
\hline Gujarat & 0.885 & 6 \\
\hline Haryana & 0.925 & 4 \\
\hline Jharkhand & 0.801 & 9 \\
\hline Karnataka & 0.877 & 8 \\
\hline Kerala & 0.881 & 7 \\
\hline Madhya Pradesh & 0.734 & 12 \\
\hline Maharashtra & 0.577 & 18 \\
\hline Manipur & 0.078 & 22 \\
\hline Meghalaya & 0.706 & 15 \\
\hline Orissa & 0.724 & 14 \\
\hline Punjab & 0.796 & 10 \\
\hline Rajasthan & 0.733 & 13 \\
\hline Tamil Nadu & 0.949 & 1 \\
\hline Uttar Pradesh & 0.659 & 17 \\
\hline Uttarakhand & 0.525 & 19 \\
\hline West Bengal & 0.932 & 3 \\
\hline Mean efficiency & 0.709 & - \\
\hline Median efficiency & 0.734 & - \\
\hline Std. Dev. & 0.232 & - \\
\hline
\end{tabular}

Source: Authors' own calculation based on secondary data 
The same table revealed the ranking of the Indian states based on efficiency scores, and the highestranking state was Tamil Nadu (0.949), followed by Delhi (0.938), and West Bengal (0.932).

\section{Analysis of stochastic frontier: factors affecting efficiency}

This section focuses on dissecting the results of the stochastic production frontier estimation. The estimation of Eqs. 2 and 3 delineated the results of the stochastic production frontier and the inefficiency effects, respectively. The SPF, as presented in Eq. 2, could be considered as the log-linear version of the Cobb-Douglas production function. Maximum likelihood estimates of the parameters were obtained using the computer program FRONTIER 4.1 [7]. These estimates, together with the t-ratio, given to three significant digits, are presented in Table 3 and also in terms of the following equations:

The estimated regression equations are as follows:

\section{Stochastic Frontier:}

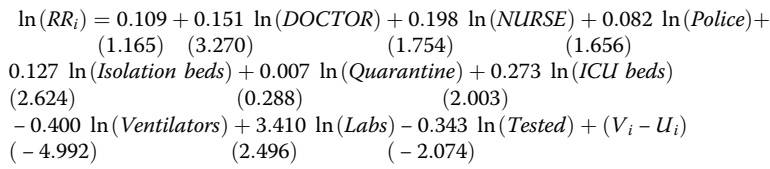

\section{Inefficiency Model:}

$U_{i}=0.920+0.952 \ln ($ Elderly $)+1.018 \ln (S R)-3.078 \ln ($ LR $)-1.689 \ln ($ Urban $)+0.050 \ln ($ Sleep $)$ $\begin{array}{lllll}(12.672)(3.150) & (2.621) \quad(-3.223) & (-2.048) & (0.050)\end{array}$ $+2.526 \ln ($ Diabetes $)+1.829 \ln ($ Heart $)-1.212 \ln$ (Population density $)-0.668 \ln ($ PCNSDP $)+$ $\begin{array}{llll}(3.591) & (2.067) & (2.059) & (-2.506)\end{array}$ $1.610 \ln ($ Employment $)-0.561 \ln ($ Digitalisation $)$

(3.201) (Employment $)-0.561 \ln (D i g$

\section{Variance Parameter:}

$$
\begin{gathered}
\hat{\sigma}_{s}^{2}=1.689 \quad \gamma=0.265 \quad \mu=0.920 \\
(2.048) \\
\log (\text { likelihood })=-6.469 \text { and } L R \text { test }=16.445 \text { and Prob }>X^{2}=0.004
\end{gathered}
$$

The absence of 'multicollinearity' was countenanced by the Additional file 1: Table S2. The Table 3 disclosed that the output variable of the SPF was 'recovery rate'. The empirical estimates of Table 3 corroborated that the coefficients of the healthcare infrastructure combatting COVID-19, namely, $\ln$ (DOCTOR), In (NURSE), In (Police), In (Isolation beds), ln (ICU beds), In (Ventilators), In (Labs), and $\ln$ (Tested) had the correct sign and were also statistically significant. These variables were widely recognised inputs for convalescence from COVID-19. The input variables $\ln$ (DOCTOR), $\ln$ (NURSE), In (Police), In (Isolation beds), In (ICU beds) and ln (Labs) positively influencing the recovery rate from COVID-19. On the contrary, the input variables $\ln$ (Ventilators) and $\ln$ (Tested) negatively affect the recovery rate from COVID-19.

In this study, the estimated coefficients in the inefficiency are of particular interest. The estimated coefficients in the inefficiency model are also presented in
Table 3 Maximum likelihood estimates of the stochastic production frontier function of performances in combating

\begin{tabular}{|c|c|c|c|c|}
\hline \multirow{2}{*}{$\begin{array}{l}\text { Variables } \\
\text { Constant }\end{array}$} & \multicolumn{2}{|c|}{ Coefficients } & \multirow{2}{*}{$\begin{array}{l}\text { S.E } \\
0.093\end{array}$} & \multirow{2}{*}{$\begin{array}{l}\text { t-ratio } \\
1.165\end{array}$} \\
\hline & $\beta_{0}$ & 0.109 & & \\
\hline $\ln (\mathrm{DOCTOR})\left(\mathrm{x}_{1}\right)$ & $\beta_{1}$ & $0.151^{\mathrm{a}}$ & 0.046 & 3.270 \\
\hline In (NURSE) $\left(x_{2}\right)$ & $\beta_{2}$ & $0.198^{c}$ & 0.113 & 1.754 \\
\hline In (Police) $\left(x_{3}\right)$ & $\beta_{3}$ & $0.082^{c}$ & 0.050 & 1.656 \\
\hline In (Isolation beds) $\left(x_{4}\right)$ & $\beta_{4}$ & $0.127^{\mathrm{a}}$ & 0.048 & 2.624 \\
\hline In (Quarantine) $\left(x_{5}\right)$ & $\beta_{5}$ & 0.007 & 0.026 & 0.288 \\
\hline In $(I C U$ beds $)\left(x_{\theta}\right)$ & $\beta_{6}$ & $0.273^{b}$ & 0.136 & 2.003 \\
\hline In (Ventilators) $\left(x_{7}\right)$ & $\beta_{7}$ & $-0.400^{\mathrm{a}}$ & 0.080 & -4.992 \\
\hline $\ln (L a b s)\left(x_{8}\right)$ & $\beta_{8}$ & $3.410^{\mathrm{b}}$ & 1.366 & 2.496 \\
\hline $\ln \left(\right.$ Tested) $\left(x_{9}\right)$ & $\beta_{9}$ & $-0.343^{b}$ & 0.166 & -2.074 \\
\hline $\ln \left(\right.$ Elderly) $\left(z_{1}\right)$ & $\delta_{1}$ & $0.952^{\mathrm{a}}$ & 0.302 & 3.150 \\
\hline $\ln (S R)\left(z_{2}\right)$ & $\delta_{2}$ & $1.018^{\mathrm{a}}$ & 0.388 & 2.621 \\
\hline $\ln (L R)\left(z_{3}\right)$ & $\delta_{3}$ & $-3.078^{\mathrm{a}}$ & 0.955 & -3.223 \\
\hline $\ln \left(\right.$ Urban) $\left(z_{4}\right)$ & $\delta_{4}$ & $-1.689^{b}$ & 0.825 & -2.048 \\
\hline $\ln \left(\right.$ Sleep) $\left(z_{5}\right)$ & $\delta_{5}$ & 0.050 & 0.997 & 0.050 \\
\hline In (Diabetes) $\left(z_{6}\right)$ & $\delta_{6}$ & $2.526^{a}$ & 0.703 & 3.591 \\
\hline $\ln \left(\right.$ Heart) $\left(z_{7}\right)$ & $\delta_{7}$ & $1.829^{\mathrm{b}}$ & 0.885 & 2.067 \\
\hline In (Population density) $\left(z_{8}\right)$ & $\delta_{8}$ & $1.212^{\mathrm{b}}$ & 0.589 & 2.059 \\
\hline $\ln (P C N S D P)\left(Z_{g}\right)$ & $\delta_{9}$ & $-0.668^{b}$ & 0.267 & -2.506 \\
\hline In (Employment) $\left(z_{10}\right)$ & $\delta_{10}$ & $1.610^{\mathrm{a}}$ & 0.503 & 3.201 \\
\hline In (Digitalisation) $\left(z_{11}\right)$ & $\delta_{11}$ & -0.561 & 0.375 & -1.497 \\
\hline$\hat{\sigma}_{s}^{2}$ & & $1.689^{b}$ & 0.825 & 2.048 \\
\hline$\gamma$ & & $0.265^{c}$ & 0.149 & 1.783 \\
\hline$\mu$ & & $0.920^{\mathrm{a}}$ & 0.073 & 12.672 \\
\hline Log (likelihood) & & -6.469 & & \\
\hline$L R$ test & & 16.445 & Prob $>$ & 0.004 \\
\hline
\end{tabular}
COVID-19 of different states of India (Dependent variable: LRR (Log of Recovery Rate) No of Observations: 20)

Source: Authors' own calculation based on secondary data

${ }^{a}$ significant at $1 \%$ level

${ }^{\mathrm{b}}$ significant at $5 \%$ level

csignificant at $10 \%$ level

Table 3. There was a positive and significant correlation with the elderly. The positive and significant estimates of sex ratio, population density, and employment infer that the antagonistic sex ratio, dense population, and underneath (regular wage/salaried employee) percentage (confirmed from 'Additional file 1: Table S1') affected the recovery rate of COVID-19 sceptically. Furthermore, higher selfreported diabetes and heart patients lower the efficiency of the state in combating COVID-19.

On the contrary, the negative and significant estimates of literacy rate, urbanisation, per-capita National State Domestic Product (NSDP), and digitalisation implied that the states with higher literacy rates, a greater proportion of 
urban areas, and improved per-capita NSDP, and improved digitalisation tended to be less inefficient.

The estimate for the variance parameter, $\gamma$, is significantly different from " 0 ", indicating that the inefficiency effects are likely to be highly significant for Indian states in combating COVID-19. It is worth noting that by the "Generalized Likelihood-Ratio" test we test the null hypothesis that the inefficiency effects are absent from the model, that is,

$$
H_{0}: \gamma=\delta_{0}=\delta_{1}=\ldots=\delta_{11}=0
$$

The corresponding test statistics has a mixed $\chi^{2}$ distribution and the corresponding probability advocates that the null hypothesis is strongly rejected. This validates the inefficiency effects of the stochastic production frontier [2] model.

\section{Discussion}

COVID-19 is spreading since December 2019. Due to the very high contamination rate of the disease, it has become a global pandemic. In India, this disease is creating a pandemonium along with drastic destruction of public health as well as the whole economy. Under such circumstances, scrutiny of the state's efficiency can significantly help understand the level of achievement. As India is a diverse country, inter-state disparities also exist at the level of achievements. Thus, this study endeavours to highlight this aspect using the stochastic production frontier model.

The ranking of the Indian states based on efficiency score divulges that the most efficient state in combatting COVID-19 is Tamil Nadu and the least efficient state in the list is Manipur. It is noteworthy that the efficiency ranks only indicate the relative performance of the states and do not indicate any hierarchy in actual health outcomes. For example, the 3rd position was occupied by West Bengal which had a relative efficiency score of 0.932. However, in terms of actual attainment, the state ranked 15th in the recovery rate from COVID-19 amongst the 22 states, with a recovery rate of $36.51 \%$.The relative health system efficiency score of the state stipulated that given its health investment, the state had accomplished approximately $93 \%$ of its prospective in resisting the spread of COVID-19. If the state's health system operated as efficiently as the most efficient state in the study, this rate could have been $95 \%$. On the contrary, if the state's health system was as inefficient as the least efficient state Manipur, the resisting ability of the state could have diminished to approximately $8 \%$, resulting in only a $12.5 \%$ recovery rate from COVID-19. This could be due to inappropriate utilisation of the available health infrastructure, leading to variations in the efficiency among different Indian states. This is the reason for the low level of health outcomes and achievements.

The absence of similar studies at the national and/or international level did not allow for cross verification of the obtained results in our study.

The empirical estimates of SFA model disclose the positive impact of the conventional health infrastructural inputs, such as $\ln$ (DOCTOR), $\ln$ (NURSE), $\ln$ (Police), $\ln$ (Isolation beds), In (ICU beds), and ln (Labs) inferred that the increase in these inputs would improve the recovery rate from COVID-19. On the contrary, the negative sign of the estimated coefficients $\ln$ (Ventilators) and $\ln$ (Tested) due to the utilisation of ventilators for serious patients and expansion of proper COVID-19 testing enabled us to identify appropriate COVID-19 affected cases. Consequently, the number of confirmed COVID-19 cases increased. The expansion of ventilators utilisation indicated an increase in serious COVID-19 cases. Simultaneously, the augmentation of proper COVID-19 tests will accelerate the number of confirmed COVID-19 cases. The cumulative effects of these two conventional health infrastructural inputs may gradually reduce the recovery rate from COVID-19. It is noteworthy that, in the prevailing circumstances, $\ln$ (Police) emerges as a predominant input variable. The positive and significant influence of the estimated coefficient reestablishes the patent fact. The positive and significant footprints of the estimated coefficient $\ln$ (Isolation beds) and $\ln$ (ICU beds) were also expected. Isolating the COVID-19 patient from others through isolation beds and ameliorated medical equipment in the multispeciality ICU would also increase the recovery rate from COVID-19.

Social, economic, and demographic variables were also included for analysis. However, these variables could not be considered input variables. Nevertheless, their influence on the efficiency of the state in combatting COVID-19 could not be disregarded. Thus, these variables were categorised as exogenous variables. These exogenous variables were considered as the drivers of efficiency. Variables such as elderly people, sex ratio, literacy ratio, population density, per capita NSDP, comorbidity rate (here self-reporting of heart disease and diabetes), regular wage earners, influenced the efficiency of the states and consequently affected the recovery rate. The positive significant correlation with the exogenous variable elderly indicated that the state with a higher percentage of older adults was more inefficient than a state with a relatively younger population. Moreover, as older adults are vulnerable to COVID-19 with a lower survival rate, this consequently leads to a lower 'recovery rate'. The results analogous to sex ratio, population density, and employment are quite apparent in the case 
of India, where the mean sex-ratio and population density $/ \mathrm{km}^{2}$ were approximately 951 and 921 , respectively. The results corresponding to the sex ratio are patently true. A population with equal and/or more proportion of the female population stipulates a favourable sex ratio. As women in Indian society are likely to stay at home, the greater female population enhances the potentiality of successful 'lockdown' without active coercion from the police force. It is a well-established fact that densely populated areas are vulnerable to community contamination of COVID-19. Thus, these two exogenous variables can predictably influence the inefficiency of the state to combat COVID-19. Furthermore, the mean (regular wage/ salaried employee) percentage for Indian states was approximately $27 \%$, indicating that a significant proportion of working adults were regular wage workers. Consequently, if they do not perform their duties, they are not eligible to receive salaries. These labour forces will certainly become a deterrent for implementing a successful lockdown. Lockdown was a globally accepted mechanism to restrict the community spread of COVID-19. For these workers, livelihood is equally important as life. In search of livelihood, these workers may unwillingly break the lockdown rule and unfortunately lead to the failure of the lockdown. The positive and significant estimates of self-reported diabetes and heart patients also reflect accurate facts. In fact, co-morbidity is one of the reasons for the poor recovery rate.

The negative and significant influence of the exogenous variables on literacy rate, urbanisation, per-capita National State Domestic Product (NSDP), and digitalisation may be due to the following reason. A higher literacy rate means the population is more aware and has a greater probability of successful 'lockdown'. Normally, urban areas are typified with modern facilities of health, law and order, social services facilities. Urban areas normally retain multispecialty hospitals with modern ICU, ventilators, a significant number of the police force and civic volunteers, social volunteers, fast internet services, and online availability of necessary goods, including medicines. A state with a greater proportion of urban areas is more efficient in combatting COVID-19. A high per-capita NSDP is a barometer of the state's prosperity. States with higher per-capita NSDP may experience upgraded health infrastructure and improved human capital (i.e., healthy and educated citizens). Thus, the likelihood of the state combatting COVID-19 is greater. This is the reason for the positive sequel of the per capita NSDP on the efficiency of the state in combatting COVID-19.

The awareness about 'do's and don'ts' related to COVID-19 is well managed through the internet. Transactions through 'net banking' and 'online purchase of necessary goods' become key constituents for ensuring a successful 'lockdown'. Consequently, the states with improved internet facilities will experience successful "Lockdown" and consequently counter COVID-19 more efficiently than other states.

It is worth noting the empirical analyses of the present paper are based on the total statistics, including both rural and urban areas of Indian states. In the case of India rural urban demarcation, specifically concerning the availability of the health care resources (doctors, nurses, hospitals etc.), is very salient. The urban India is more equipped with all kinds of health care resources (doctors, nurses, hospitals etc.) and as expected to be more efficient to combat COVID-19. Consequently a separate analysis for rural and urban India is always better. Unfortunately, non-availability of the relevant statistics dictated us to consider total statistics (considering both rural and urban together) for the empirical analyses. However, we have considered "Urbanisation" as one of the exogenous variable to apprehend the role of "Urbanisation" in the efficiency in combating COVID-19. This is definitely a limitation of this study. Moreover, the ranking of the states remains invariant because the efficiency scores of the states are obtained by using the FRONTIER-4.1 programme.

\section{Conclusion}

This study is predominantly empirical. The empirical results allow us to confirm the existence of interstate disparities in the efficiency in combatting COVID-19 across India. This was evident in the variation in the recovery rate across Indian states. Various social, economic, and demographic variables increased the efficiency of states in combatting COVID-19. Based on our empirical results, we suggest the following policy prescriptions:

First, as it is evident that the health infrastructure inputs, such as doctors, nurses, police, isolation beds, ICU beds, help the state escalate the recovery rate from COVID-19. Therefore, improvements in the health infrastructure will act as catalysts in fighting the pandemic and the health system as a whole in the long-term. Doctors, nurses, and police should be sufficiently provided with required medicines and relevant safety measures as they are frontline workers in this COVID-19 pandemic. Second, the exogenous variable, the elderly population, is a major component contributing to inefficiency. As they are more vulnerable to disease, utmost care should be provided to them along with required medical treatment and nutritious foods. Third, as population density may negatively affect efficiency, areas with dense populations may be considered for special surveillance to minimise contamination. Fourth, regular wage earners are in search of their livelihoods, and may unknowingly 
cause the lockdown to fail. These activities not only enhance the likelihood of their contamination but also community spread. To avoid such circumstances, it is highly recommended to arrange an alternative livelihood for them temporarily so that they stay at home and help in completing the lockdown successfully. Simultaneously, for salaried people, it is necessary to arrange work from home so that they can continue their duties to ensure the economy is running. Finally, in these days of hardship, the government of all states along with the centre should be very effectively controlling the damage, assuring the citizens' safety and provision of requirements accordingly.

As mentioned earlier the empirical analyses of the present paper are based on the total statistics, including both rural and urban areas of Indian states. Depending on the availability of the data the paper can be extended considering rural and urban areas across Indian states in future.

\section{Supplementary Information}

The online version contains supplementary material available at https://doi. org/10.1186/s12889-020-10051-6.

Additional file 1: Table S1. Descriptive statistics of output, input and exogenous variables. Table S2. Correlation Matrix.

\section{Abbreviations}

WHO: World Health Organization; UNO: United Nations Organisations; SFA: Stochastic frontier analysis; SPF: Stochastic production frontier: ICU: Intensive care unit; NSDP: National State Domestic Product

\section{Acknowledgments}

We would like to extend our special thanks of gratitude to the Editage (www. editage.com) for English language editing. We also express our heartfelt gratitude to our institutional authorities for their cooperation. We are extremely grateful to the anonymous respected reviewers for their valuable comments to improve the quality of the paper. Finally, we express our indebtedness to the journal manager Dr. Jeemon Panniyammakal and Dr. John Feigelson of BMC Public Health without his kind cooperation it not possible to complete this work timely by maintaining the quality.

\section{Authors' contributions}

S.M., conceived of the study, participated in its design and coordination, performed the statistical analyses, and drafted the manuscript; N.G., participated in the design and helped to draft and revised the manuscript. U.R.B., helped in data compilation. All authors read and approved the final manuscript.

\section{Funding}

This research did not receive any specific grant from any funding agencies in the public, commercial, or not-for-profit sectors.

\section{Availability of data and materials}

The study is based on the secondary data and all the data sources are clearly mentioned in the text. For further details kindly consult Table 1.

Ethics approval and consent to participate

Not applicable

\section{Consent for publication}

Not applicable

\section{Competing interests}

The authors declared and specified that they have no competing interest and/ or conflict of interest.

\section{Author details}

'Department of Economics, Vidyasagar University, Paschim Midnapore, Midapore, West Bengal, India. ²Department of Microbiology, Vidyasagar University, Midnapore, West Bengal, India. ${ }^{3}$ Department of Economics, Assam University, Silchar, Assam, India.

Received: 1 September 2020 Accepted: 10 December 2020

Published online: 29 December 2020

\section{References}

1. Battese GE, Coelli TJ. A stochastic frontier production function incorporating a model for technical inefficiency effects, Working Papers in Econometrics and Statistics; 1993. p. 69.

2. Battese GE, Coelli TJ. A model for technical inefficiency effects in a stochastic frontier production function for panel data. Empir Econ. 1995; 20(2):325-32.

3. Becker GS. The economic way of looking at life. [Nobel Lecture]. Chicago: University of Chicago Department of Economics; 1992.

4. Brufsky A. Hyperglycemia, hydroxychloroquine, and the COVID-19 pandemic. J Med Virol. 2020; 2020 Apr 15.

5. Chirikos TN. Further evidence that hospital production is inefficient. Inquiry. 1998 Dec;1:408-16.

6. Chirikos TN, Sear AM. Measuring hospital efficiency: a comparison of two approaches. Health Serv Res. 2000;34(6):1389-408.

7. Coelli TJ. A guide to FRONTIER version 4.1: a computer program for stochastic frontier production and cost function estimation, vol. 7; 1996. p. 1-33. CEPA Working papers.

8. Datta M, Neogi C. Reform raises efficiency of oil refining public sector enterprises in India. Indian Econ Rev. 2013:239-61.

9. DeFelice LC, Bradford WD. Relative inefficiencies in production between solo and group practice physicians. Health Econ. 1997;6(5):455-65.

10. Evans DB, Tandon A, Murray CJ, Lauer JA. The comparative efficiency of national health systems in producing health: an analysis of 191 countries. World Health Org. 2000;29(29):1-36.

11. Factsheet, I. National family health survey (NFHS-4) 2015-16. Mumbai: International Institute for Population Sciences (IIPS); 2017. [cited 2018 Sep 07]. India. pdf. [Google Scholar].

12. Forbes M, Harslett P, Mastoris I, Risse L. Measuring the technical efficiency of public and private hospitals in Australia. In: Australian conference of economists; 2010. p. 27-9.

13. Gerdtham UG, Löthgren M, Tambour M, Rehnberg C. Internal markets and health care efficiency: a multiple-output stochastic frontier analysis. Health Econ. 1999 Mar;8(2):151-64.

14. Hamidi S. Measuring efficiency of governmental hospitals in Palestine using stochastic frontier analysis. Cost Effectiveness Resour Allocation. 2016;14(1):3

15. Hofler RA, Rungeling B. US nursing homes: are they cost efficient? Econ Lett. 1994:44(3):301-5.

16. https://www.thehindu.com/news/national/coronavirus-liveupdatesmarch-24-2020/article31149240.ece. Accessed 21 Feb 2020.

17. INDIA, P. Census of India 2011 provisional population totals. New Delhi: Office of the Registrar General and Census Commissioner; 2011.

18. Kathuria V, Sankar D. Inter-state disparities in health outcomes in rural India: an analysis using a stochastic production frontier approach. Dev Policy Rev. 2005;23(2):145-63.

19. Lu H, Nie P, Qian L. Do quarantine experiences and attitudes towards COVID-19 affect the distribution of mental health in China? A quantile regression analysis. Appl Res Qual Life. 2020:1-18.

20. Maity S. A study of measurement of efficiency. Germany: VDM VerlagDr. Muller GmbH \& Co. KG; 2011. ISBN-978-3-639-33741-9.

21. Maity S, Neogi C. Production of tea in Assam and West Bengal: technical inefficiency effects. ArthaVijnana. 2014;56(4):479-99.

22. Murray C, Frenk J. World health report 2000: a step towards evidence-based health policy. Lancet. 2001;357(9269):1698-700.

23. National Sample Survey Office. (2013). Key indicators of employment and unemployment in India 2011-12, 68th round. 
24. RBI, R. (2018). Handbook of statistics on Indian states. Retrieve from: https:// www.rbi.org.in/Scripts/AnnualPublications.aspx?head=Handbook+of+ Statistics+on+Indian+States. Accessed on: 12 2020.

25. Sankar D, Kathuria V. Health system performance in rural India: efficiency estimates across states. Econ Polit Wkly. 2004:1427-33.

26. Schultz TP. The economic value of education, Columbia University Press. The European institution for life long learning, La théorie du capital humainet le gouvernementd'entreprise; 1963. p. 2-7.

27. Stevenson RE. Likelihood functions for generalized stochastic frontier estimation. J Econ. 1980;13(1):57-66.

28. Street A, Jacobs R. Relative performance evaluation of the English acute hospital sector. Appl Econ. 2002;34(9):1109-19.

29. United Nations Organisation. (2019a). "Overall total population" - world population prospects: the 2019 revision (xs|x). population.un.org (custom data acquired via website). United Nations Department of Economic and Social Affairs, Population Division. Retrieved November 9, 2019.

30. United Nations Organisation. (2019b). "Total Population - Both Sexes". World Population Prospects, the 2019 Revision. United Nations Department of Economic and Social Affairs, Population Division, Population Estimates and Projections section. June 2019. Retrieved 17 June 2019.

31. United Nations Organisation. (2019c). "World population prospects population division". population.un.org. United Nations Department of Economic and Social Affairs, Population Division. Retrieved November 9, 2019.

32. Wagstaff A. Estimating efficiency in the hospital sector: a comparison of three statistical cost frontier models. Appl Econ. 1989;21(5):659-72.

33. Word Bank. 2014. URL https://data.57worldbank.org. Accessed 23.07.2015.

34. World Health Organization. Coronavirus disease (COVID-19) outbreak. 2020 URL https://www.WHO.int/emergencies/diseases/novel-coronavirus-2019. Accessed 22 Feb 2020.

35. Yildiz MS, Heboyan V, Khan MM. Estimating technical efficiency of Turkish hospitals: implications for hospital reform initiatives. BMC Health Serv Res. 2018;18(1):401.

36. Zuckerman S, Hadley J, lezzoni L. Measuring hospital efficiency with frontier cost functions. J Health Econ. 1994;13(3):255-80.

\section{Publisher's Note}

Springer Nature remains neutral with regard to jurisdictional claims in published maps and institutional affiliations.

Ready to submit your research? Choose BMC and benefit from:

- fast, convenient online submission

- thorough peer review by experienced researchers in your field

- rapid publication on acceptance

- support for research data, including large and complex data types

- gold Open Access which fosters wider collaboration and increased citations

- maximum visibility for your research: over $100 \mathrm{M}$ website views per year

At $\mathrm{BMC}$, research is always in progress.

Learn more biomedcentral.com/submissions 